\title{
PERSPECTIVAS PARA O ENSINO NA SAÚDE: DO ‘APAGÃO EDUCACIONAL’ À POLÍTICA DE EDUCAÇÃO PERMANENTE
}

\author{
PROSPECTS FOR TEACHING IN HEALTH: FROM THE 'EDUCATION BLACKOUT' TO THE CONTINUING \\ EDUCATION POLICY
}

PERSPECTIVAS PARA LA ENSEÑANZA EN LA SALUD: DEL 'APAGÓN EDUCATIVO' A LA POLÍTICA DE EDUCACIÓN PERMANENTE

Renata de Lima Pacheco Nideck ${ }^{1}$

Paulo Pires de Queiroz ${ }^{2}$

Resumo O artigo aborda a educação permanente na ótica reflexiva e rizomática, abrangendo a necessidade de desterritorializar os saberes circulantes na saúde. Trata-se de pesquisa bibliográfica cujo referencial teórico estrutura-se no materialismo histórico marxista. O estudo descreve um breve histórico sobre a política educacional com base em dois eventos marcantes ocorridos na década de 1980: a escassez de trabalhadores para o trabalho complexo, denominado 'apagão educacional', e o surgimento do novo ensino superior no Brasil. Tais eventos, ao atravessarem a formação profissional, reproduzem na educação em serviço a estrutura do conhecimento mais hierarquizada. Se o ensino na saúde apresenta limitações, oferece também possibilidades e perspectivas para romper com a rigidez epistemológica e aproximar-se da educação menor e do crescimento de rizomas nas práticas em saúde.

Palavras-chave educação permanente; SUS; profissional reflexivo; educação menor; pedagogia rizomática.
Abstract The article discusses continuing education from reflective and rhizomatic perspective, covering the need to deterritorialize the current knowledge on health. It is a review of the literature the theoretical reference for which is structured in historical Marxist materialism. The study describes a brief history of the educational policy based on two landmark events in the 1980s: A shortage of workers for complex work, which was called an educational blackout, and the emergence of new higher education in Brazil. Such events, when traversing professional training, reproduce the more hierarchical structure of knowledge in education in work. While teaching in health has limitations, it also offers possibilities and perspectives to break away from the epistemological rigidity and to approach the lower education and growth of rhizomes in health practices.

Keywords continuing education; UHS; reflective practitioner; lower education; rhizomatic pedagogy. 


\section{Um breve histórico da década de 1980}

A cada ano, novos profissionais diplomados saem das universidades em busca de emprego. Este seria um fato animador, se as estatísticas não alimentassem o mercado de trabalho precário.

São cerca de 10 mil médicos; 8.300 dentistas; 32 mil enfermeiros; 11.900 farmacêuticos; 7.700 nutricionistas e 16 mil fisioterapeutas que concluíram seus respectivos cursos, totalizando 85.900 formandos, ou seja, um número 3,78 vezes maior que o total de 22.643 profissionais diplomados em 1992 (Machado, Oliveira e Moysés, 2013). Para compreender essa expansão de profissionais graduados no setor saúde, precisamos retroceder à década de 1980 na formação do novo perfil para o ensino superior no Brasil (ESB).

Para a sociologia, os anos 1980 marcaram uma década conturbada, cheia de contrastes político-econômicos e perplexidades sociais. A globalização, o autoritarismo econômico, as relações de poder, o avanço tecnológico, a desterritorialização dos espaços, o 'americanocentrismo', a apropriação da cultura de massa, o consumismo, a depredação ambiental e a violência social constituíram na história do tempo presente uma paradoxal relação de amor e ódio, de 'claro-escuro', inaugurando a crise da modernidade e a transição dos paradigmas societais e epistemológicos (Santos, 2008).

Em consonância com o contexto histórico internacional, a sociedade brasileira também partilhava as contradições dessa década ao conjugar a implantação do Estado democrático de direito numa atmosfera social excludente permeada por analfabetismo, desemprego, miséria, epidemias, violência ambiental e indígena, crise econômica e política etc. No consenso do empresariado, da intelectualidade e dos políticos, havia urgência em superar os paradigmas político-institucionais conservadores e os resquícios de autoritarismo do serviço público. $\mathrm{O}$ atraso educacional refletido na formação do trabalhador e no processo de trabalho precisava ser corrigido conjuntamente com as políticas sociais (Neves e Pronko, 2008).

Aos saberes pedagógicos agregavam-se, nesse momento, importantes contribuições da sociologia, da antropologia, da filosofia e da economia. Somavam-se forças para romper com o modelo, até então vigente, de educação vinculada à divisão técnica e social do trabalho. Nessa ótica, convergiram diferentes olhares, concepções, análises, tendências a reivindicar mudanças nas diretrizes da educação nacional em atenção a uma nova aurora educacional mais crítica, criativa, participativa e democrática (Neves e Pronko, 2008, p. 49).

O debate em torno da organização da sociedade democrática priorizava a escolarização de grande parcela do Estado para a formação intensiva de mão de obra e a implementação de projetos educacionais sistemáticos. Para Neves (2000, apud Neves, 2008, p. 56), “nunca antes no Brasil o Estado 
interveio tão rápida e organicamente na formação de um novo tipo de trabalhador e homem". A lógica difundida era bastante clara: a massa trabalhadora precisava ter acesso à escolarização básica e técnico-profissional centrada no binômio pobreza/segurança para manutenção de uma política de paz no universo capitalista (Neves e Pronko, 2008).

Essas diretrizes nas políticas gerais e setoriais faziam parte das intervenções 'neodesenvolvimentistas' defendidas pelos organismos internacionais para os países periféricos latino-americanos. O Banco Mundial, a Organização Mundial do Comércio e o Banco Interamericano de Desenvolvimento compatibilizavam suas políticas de empréstimos à implantação de reformas para aceleração do crescimento. Esse discurso subordinava o desenvolvimento econômico ao investimento em capital humano, composto por escolaridade, treinamento e saúde do trabalhador. Nessa ótica linear julgava-se necessário remover da educação certos entraves político-institucionais mantidos até então pela estrutura autoritária de governo, como as desigualdades sociais, o sucateamento orçamentário, a redução do número de matrículas, a exclusão educacional das maiorias pauperizadas, a produção de alta cultura em detrimento da cultura de massa (Frigotto, Ciavatta e Ramos, 2009; Neves, 2008).

Somadas a esse rol de entraves, havia também as críticas da burguesia empresarial sobre a produção deficiente de trabalhadores qualificados para suprir a demanda do mercado de trabalho, nesse momento aquecido. Estima-se que mais de 18 milhões de novos postos de trabalho foram criados nessa década (Urani, 1995, apud Farago e Sampaio, 2009). O crescente número de vagas nas empresas sem profissionais suficientes para preenchê-las foi denominado pela alta administração do governo e pelos proprietários dos meios de produção de 'apagão educacional' (Neves, 2008).

O termo 'apagão educacional' carrega em si análises conflitantes, sem unicidade conceitual. No campo da reflexão marxista, por exemplo, o atraso educacional nas economias capitalistas não provém de entraves institucionais ou relações sociais desiguais; ele é determinado pela estrutura econômica. A exclusão evidencia as contradições do próprio sistema no processo de acumulação de capital e que levarão ao seu esgotamento. Já na análise marxista não ortodoxa, as contradições entre as forças produtivas e as relações de produção convertem-se em contingências, juntamente com os fatores políticos e culturais. Estes favorecem a exclusão e iniquidades sociais, mas não as determinam. Já o capitalismo na lógica neoliberal vê o apagão como um fator de impedimento para a mundialização do mercado. Assim como outras crises cíclicas, o apagão requer medidas de ajuste e regulação ao sistema, como ocorrido com o fordismo, o keynesianismo e as políticas do estado de bem-estar social (Santos, 2008; Neves, 2008; Frigotto, Ciavatta e Ramos 2009). Para fins de análise, este artigo situa suas concepções e seus desdobramentos no terreno marxista, partindo da premissa de que o 
capitalismo do século XXI não coloniza somente a força produtiva, mas também os valores, desejos e crenças.

Nessa perspectiva, o apagão educacional na década de 1980 foi enfrentado com base em políticas educacionais distintas que seguiram em duas direções, uma conservadora e outra inovadora. A primeira, vinculada às instituições públicas federais, estaduais e algumas confessionais, com preservação dos direitos conquistados pela reforma de 1968, conquistas essas englobando a valorização do ensino e pesquisa na formação acadêmica, a criação de departamentos, a extinção da cátedra vitalícia, a profissionalização do docente e, principalmente, a política nacional de pós-graduação. A segunda concorreu para a reversão do apagão educacional pela via privada, um ajuste à demanda do trabalho complexo que a reforma de 1968 não deu conta de corrigir - um desdobramento denominado na literatura de 'novo ensino superior privado' (Martins, 2009, p. 23). Esse conceito refere-se às instituições de perfil laico vinculadas até o final da década de 1980 à educação básica e transformadas, posteriormente, em centros integrados, faculdades e universidades particulares motivadas pela necessidade de se expandir o número de vagas no ensino superior, pela política de incentivo ao setor complementar acrescida da mentalidade empresarial dos proprietários (Martins, 2009, p. 23).

No formato organizacional mais flexível, 'o novo ensino superior' veio favorecer uma clientela socialmente diferenciada, jovens não matriculados nas instituições públicas de ensino e adultos integrados no mercado de trabalho. De maneira oportuna, tais segmentos procuraram adequar o ensino à necessidade do estudante/trabalhador, na profissionalização generalista. O investimento acadêmico vinculou-se à promessa de ascensão profissional, formando um único ciclo de formação e produção. A relação ensino, pesquisa e extensão foi dando lugar às expertises tecnológicas e informacionais para o mercado de trabalho (Martins 2009, p. 23).

Para Antunes (2001), no capitalismo contemporâneo, a classe-que-vive-do-trabalho 3 não só vende sua força de trabalho, mas procura corresponder à sociedade do conhecimento. ${ }^{4}$ Entende-se por sociedade do conhecimento uma organização social que contemple a democratização do saber, a formação de indivíduos autônomos, a equidade de condições no mercado de trabalho. Subentende-se também a formação integral, humanista, sem a hierarquização dos saberes técnico-científicos. No entanto, a estrutura capitalista converteu a sociedade do conhecimento no modelo empresarial de competências, competitividade, desempenho e flexibilização.

A elevação da qualificação formal, além de contribuir para novas lógicas produtivas, que exigem habilidades e saberes tecnológicos, minimiza as relações de poder, as lutas de classe na esfera do trabalho e, acima de tudo, isenta o Estado de qualquer responsabilidade sobre as políticas públicas 
geradoras de emprego. Esse movimento tende a desconsiderar a crise de reestruturação do trabalho e seus fatores determinantes e reproduzir a ideia de sucesso e fracasso como responsabilidades individuais sem implicação da macroestrutura estatal. O fetiche em torno da sociedade do conhecimento sustenta o pensamento equivocado de que o desemprego só existe para quem não tem qualificação (Radzinski, 2007, apud Farago e Sampaio, 2009).

O resultado dessa 'modernização conservadora' se configura na expansão de cursos gerenciados pela necessidade do mercado de trabalho (técnico ou profissional), na adequação do conteúdo programático e do estágio curricular às necessidades do discente, na estrutura administrativo-acadêmica voltada para a formação de profissionais, dissolvendo a relação ensino, pesquisa e extensão, bem como na desvalorização do ensino público como uma proposta educacional ineficiente, ideologicamente tendenciosa e desprovida de competitividade, como se a educação fosse apenas uma das commodities (mercadorias) das relações de consumo (Apple, 2005).

Cabe considerar que esse novo modelo não se produziu nem se desenvolveu à margem das circunstâncias e das condições que a época apresentava, tanto sociais como intelectuais e culturais. A diplomação profissional virou moeda de troca circulando pelos espaços e se configurando de acordo com a expectativa do mercado e o anseio da classe trabalhadora, sem contestar a hegemonia dominante ou a qualidade educacional ofertada (Apple, 2005).

Abrem-se parênteses para argumentar que tal lógica de mercantilização da educação alcançou também o trabalho docente na esfera pública. Esse fenômeno foi facilmente detectado pela elevada privatização dos cursos de pós-graduação lato sensu, pela inserção indiscriminada do ensino a distância, pela precarização nas relações de trabalho (escassez de concursos, retração do regime de dedicação exclusiva, crescimento dos contratos temporários, regime hora/aula etc.) e pela pressão dos órgãos de fomento e de avaliação de pesquisa à produtividade por meio de bolsas de pesquisa, relatórios, publicações, indexação de cursos, periódicos e do saber voltado para a relevância mercadológica. São exemplos de aprisionamento dos espaços do saber em estratégias de gestão do conhecimento para a formação de competências, profissionalização em massa e garimpagem de talentos (Bosi, 2009, p. 1517).

O boom educacional da década de 1980 trouxe a elevação da escolaridade na área de saúde. Fontes do Instituto Brasileiro de Geografia e Estatística entre 1992 a 2005 revelam que os índices mais significativos ocorreram na inserção de enfermeiros no mercado de trabalho, com um crescimento de 179,8\% (Machado, Oliveira e Moysés, 2013, p. 4). Os dados poderiam ser considerados exitosos se não corroborassem a análise de Nunes (2012) sobre os desafios da expansão do ensino superior no Brasil e a deficiência em conferir ao estudante uma formação generalista de qualidade e aporte necessário para o mercado de trabalho complexo. 
Os dois caminhos, das instituições de ensino superior nos moldes da reforma universitária e do 'novo ensino superior', não conseguem contemplar as exigências da sociedade e do mundo do trabalho em transição, um perseguindo o saber instrumental, a investigação, a abstração teórica, o método experimental, a centralidade acadêmica afastada da empiria e da coletividade; outro ancorado na gestão do conhecimento, em saberes utilitários que atendam aos espaços de produção. Os referidos modelos evidenciam uma lacuna na interface educação-trabalho, como se não fossem um extensão do outro. Essa lacuna conduz ao pensamento equivocado de que o profissional chega ao mundo do trabalho pronto, acabado, com um arcabouço cognitivo suficiente e definido, como se o processo de formação profissional fosse imune às práticas cotidianas, às situações adversas, ao encontro dos saberes, às lutas de poder etc.

Contemplar a interface educação e trabalho na perspectiva deleuze-guattariana significa resistir ao empreendimento de educação para a empregabilidade e reconhecer o ato de aprender como tarefa infinita. Uma tarefa que foge do controle e escapa dos métodos. Portanto, não basta implementar parâmetros, diretrizes, política de educação permanente, indicadores de qualidade; o importante é lançar as sementes, desterritorializar os saberes, fugir do domínio historicamente pactuado, seja do mundo ilustrado da educação, seja do mundo pragmático do trabalho, para ocupar o 'inter', o meio, o intermezzo, e de dentro da máquina educacional opor resistência (Gallo, 2008).

\section{O SUS nosso de cada dia}

O Sistema Único de Saúde (SUS) é um acontecimento. Um acontecimento na perspectiva deleuzeana pode ser um momento da efetivação, quando o acontecimento encarna um estado de coisas em que o passado e o futuro se fundem em função desse presente, como pode também o futuro e o passado se esquivarem desse estado de coisas do presente e extrapolarem o limite do acontecimento (Zourabichvili, 2009). Portanto, não é possível compreender o SUS sem refletir sobre as forças ideológicas conflitantes imbricadas no projeto sanitário desde seu nascedouro - forças essas procedentes do pensamento neoliberal e privatista na saúde, do movimento popular setorizado, da divisão social do trabalho, da crise nas universidades públicas, da demanda de mão de obra para o trabalho complexo, da sociedade do conhecimento no modelo empresarial etc. Para Boaventura de Sousa Santos (2008), são relações de 'amor e ódio', 'claro e escuro', provenientes da década de 1980 e presentes até hoje na crise societal. 
Mas, de fato, o que é o SUS? O que perpassa esse acontecimento? Na definição do Portal da Saúde o SUS é "um dos maiores sistemas públicos de saúde do mundo". Não temos dúvidas quanto a isso, mas apesar da observância jurídico-normativa, entender o funcionamento de um sistema que tem por missão garantir assistência integral à saúde para uma população com cerca de duzentos milhões de habitantes requer rupturas e ressignificações para toda a sociedade. Rupturas com o antigo modelo de saúde vinculado à Previdência Social, com a restrição do direito à saúde, com a lógica curativa, com o predomínio do setor secundário e terciário (hospitalocêntrico), com a falta de equidade e humanização dos serviços. A mudança paradigmática compreende a gênese do SUS; ele nasce da Conferência de Alma-Ata, 5 do movimento popular, da luta contra a ditadura, do compromisso com a universalidade da saúde (Saldanha, 2011).

Em termos de distribuição espacial, ele está presente nos 5.564 municípios brasileiros, distribuídos pelas 27 unidades federativas. Em termos de circulação de capital, também apresenta relevância na economia do país.

O setor saúde é um ramo importante na economia brasileira - representa 4,3\% da população ocupada no país, gerando mais de $10 \%$ da massa salarial do setor formal, e em torno de 3,9 milhões de postos de trabalho (2,6 milhões de vínculos formais, 690 mil sem carteira assinada e 611 mil profissionais autônomos (Instituto Brasileiro de Geografia e Estatística, 2006).

Na definição de sistema único de saúde, temos um conjunto de instituições políticas e sociais, com métodos e ações práticas direcionadas para uma finalidade: garantir saúde universal, integral, em equidade de condições para todos os brasileiros. Tal sistema tem uma legislação única que rege a saúde em todo o território nacional. Trata-se da lei n. 8.080, de 19 de setembro de 1990 (Brasil, 1990), que dispõe sobre as condições para a promoção, a proteção e a recuperação da saúde, a organização e o funcionamento dos serviços correspondentes e dá outras providências. Além da lei orgânica, temos a lei n. 8.142, de 28 de dezembro de 1990, que também dispõe sobre a participação da comunidade e transferências intergovernamentais; consta ainda o artigo $6^{\circ}$ da lei n. 8.689, de 27 de julho de 1993, da Criação do Sistema Nacional de Auditoria, no âmbito do SUS, e de decretos, portarias e normas operacionais básicas no SUS (NOBs 91/93/96), normas operacionais de assistência à saúde (Noas 01/01 e 01/02) e Pacto pela Saúde (Saldanha, 2011).

O SUS estrutura-se em três princípios doutrinários: universalidade, integralidade e equidade. Saúde universal no sentido constitucional de direito de todos e dever do Estado. Vale salientar a história institucional de saúde 
pública no Brasil com bases conflitantes, ora welfare state, ora em investidas neoliberais. Tal panorama contraditório se expressava pela exclusão de populações sem vínculos previdenciários, monopólio de rede conveniada de caráter privado, ampliação da rede hospitalar no modelo médico-assistencial, bolsões de desassistidos etc. Em relação à integralidade, refere-se às necessidades do usuário (como sujeito da ação) e à garantia de acesso a todos os níveis do sistema de serviços de saúde. Essa garantia envolve respostas às demandas do sujeito, acolhimento, escuta, comunicação eficaz, domínio teórico dos profissionais, rede de referências, flexibilizações das rotinas, fluxos dos usuários, adequação às situações singulares etc. E o conceito de equidade envolve ações que visem minimizar as diferenças em consonância com a justiça social, priorizando a atenção primária para populações desassistidas, em bolsões de pobreza e áreas endêmicas (Saldanha, 2011).

Em relação aos princípios operacionais, temos a descentralização, a regionalização, a regulação, a participação popular, a hierarquização dos níveis de atenção e a complementaridade do setor privado. A extensa rede de serviços envolve: proteção, promoção e recuperação da saúde; vigilância sanitária e epidemiológica; controle e aquisição de medicamentos; assistência terapêutica integral, inclusive farmacêutica; saúde do trabalhador; política e execução de ações de saneamento básico; vigilância e orientação nutricionais; ordenação da formação de recursos humanos na área de saúde; fiscalização de alimentos, água e bebidas para o consumo humano; produção e fornecimento de insumos; educação, pesquisa e tecnologia, dentre outras ações.

A participação da comunidade está presente no panorama constitutivo do SUS. Este princípio traz algo de inédito para a saúde pública no Brasil: o direito da comunidade de se expressar e intervir na tomada de decisões presente na Carta de Alma-Ata. Talvez seja esta a mais significante reivindicação do movimento sanitário. O controle social tem caráter consultivo, se estabelece por meio de conferências e conselhos em âmbitos local e nacional. A representação de diversos segmentos da sociedade compreende usuários, profissionais de saúde (associações, sindicatos etc.), gestores e delegados do setor suplementar. Longe de ter alcançado o direito deliberativo, o controle social no SUS deve reorientar a estrutura organizacional na perspectiva do usuário e dos trabalhadores em saúde. Esse não é um processo natural e instantâneo, requer desconstrução de práticas e valores no que se refere à gestão 'com' a comunidade em lugar de 'para' a comunidade, e a concretude desse empoderamento precisa ser vigilante e responsável para que não se torne uma nova máquina de privilégios e favores.

Sem dúvida, nessas duas décadas o SUS vem se consolidando e apresentando avanços nos indicadores de saúde, com o crescimento da cobertura da Estratégia Saúde da Família, a implementação da regulação dos atendimentos de urgência, o Serviço de Atendimento Móvel de Urgência (Samu), a dimi- 
nuição da mortalidade infantil e materna em todos os estados da federação, por exemplo. Mas universalizar a saúde com integralidade e equidade torna-se um grande desafio diante do panorama nacional marcado pela heterogeneidade e pelos contrastes sociais, em que $17 \%$ da população brasileira não lê ou lê com dificuldade. São mais de 16 milhões de analfabetos, e metade deste número está concentrada em menos de $10 \%$ dos municípios do país.

Em relação ao retrato de saúde dos brasileiros, o Relatório Saúde Brasil 2009 (Brasil, 2009) - uma análise da situação nacional e internacional de prioridades, como nasce, cresce, adoece e morre a população do nosso país -, observamos mudanças significativas nos padrões de fecundidade, de combate às doenças infecciosas e crônicas, de mortalidade infantil etc. Embora os índices sejam otimistas e a população brasileira esteja vivendo mais e com melhor qualidade, ainda necessitamos relacionar esses índices ao poder tutelar que investe em projetos emergenciais desvinculados do processo de consolidação da cidadania.

Outros entraves envolvem a eficácia do sistema e a sua plena universalidade, como a exclusão de populações em situação de risco (profissionais do sexo, população carcerária, viciados em drogas ilícitas etc.). A integralidade requer a eficácia de um sistema operacional em rede; os serviços ainda não se comunicam de forma efetiva, o que impede o fluxo dos usuários pelos diversos níveis de complexidade, caracterizando um 'gargalo operacional'. Quanto às demandas excepcionais, como medicamentos, exames, procedimentos cirúrgicos, próteses e terapias experimentais, ainda requerem ações judiciais, fenômeno conhecido por judicialização da saúde, incorrendo em filas na Defensoria Pública ou honorários advocatícios, custas judiciais e espera diante de agravos que exigem celeridade.

A problemática que envolve os serviços prestados pelo SUS frequentemente circula no debate acadêmico, tanto que no X Congresso de Saúde Coletiva, realizado em Porto Alegre no ano de 2012 com a temática "Saúde é desenvolvimento: ciência para a cidadania", ao se abordar o abandono do tratamento das doenças não transmissíveis, elencou-se a escassez de consultas, a interrupção no fornecimento dos medicamentos e a falta de informação sobre as comorbidades, somada à ausência de incentivo por parte da equipe e familiares. Esses dados possibilitam a reflexão sobre o papel da saúde como direito de todos e sua corresponsabilidade no processo de desenvolvimento social.

Para além de estratégias produtivas que fomentem os indicadores de saúde, a acessibilidade, a comunicação em rede, os recursos informacionais, o SUS precisa considerar também o elemento humano nas ações em saúde - o trabalhador protagonista. A Vigilância em Saúde do Trabalhador no setor saúde apresenta em suas análises quatro polos conceituais referentes ao processo de trabalho. São eles: saúde - a situação de saúde dos trabalhadores apresenta alta prevalência de adoecimento por transtornos mentais, absenteísmo-doença, 
doenças osteomusculares referentes ao trabalho (dorts) e acidentes relacionados à contaminação biológica; atividade - este conceito incorpora a saúde ao processo de trabalho; são situações que envolvem riscos químicos, físicos, biológicos, psicológicos e sociais; território - este é o espaço de encontro onde as relações acontecem; e vulnerabilidade - este polo significa um campo de forças incluindo riscos das condições de trabalho, mediado pela capacidade de resiliência e o contexto social (Assunção e Brito, 2011).

Em relação ao risco social da atividade em saúde, vale ressaltar a precarização do trabalho. Trata-se de um fenômeno mundial caracterizado pela exploração da mais-valia, pela obtenção de lucros e pela supressão de direitos e garantias trabalhistas. Para Antunes (2004, p. 9), “o trabalhador frequentemente não se satisfaz no trabalho, mas se degrada; não se reconhece, mas muitas vezes recusa e se desumaniza no trabalho". Hoje, a revolução tecnológica, ao impor a reestruturação das forças produtivas, impõe também um perfil profissional que atenda ao fenômeno da precarização como parte da flexibilização do mercado de trabalho. Isto significa dizer que a inserção do profissional nesse mundo do trabalho prevê um perfil de formação produtivista, competitivo, desprovido de criticidade, de forma a atender às exigências do mercado de trabalho.

Desde 2003, o Ministério da Saúde já admite a existência da precarização do trabalho no SUS como um fenômeno que interfere em sua sustentabilidade e que deve ser enfrentado de forma sistematizada por meio do Programa Nacional de Desprecarização do Trabalho no SUS (Desprecariza-SUS). O termo precarização do trabalho no SUS refere-se a diversas mutações de caráter flexível nas relações de trabalho, como prestação de serviço, trabalho por tempo determinado, terceirizações, cooperativas etc. - uma diversidade contratual que implica perda de direitos, desvinculação da relação pedagógica do trabalho, discriminação, exclusão social, subemprego, como também a sujeição patronal e o enfraquecimento sindical que impede mobilização e resistência coletivas dos trabalhadores.

Na condição de política pública em vigor desde 2006, o programa Desprecariza-SUS permanece na esfera da normatização distante do sentido cognitivo da proposta. Suas ações e estratégias não enfrentam o problema no contexto estrutural e também não buscam integração entre a educação e o serviço. Os dispositivos legais são ineficazes diante da lógica neoliberal e da demanda de flexibilização do mundo globalizado.

\section{Educação, trabalho e saúde}

A desproporção entre o número de profissionais qualificados e a demanda para o trabalho complexo na década de 1980, conhecido como apagão edu- 
cacional, se fez presente em todos os setores de serviços, inclusive no SUS. Assim, as políticas no campo da educação procuraram modificar o quadro com a profissionalização em massa dos trabalhadores alicerçada na pedagogia das competências. As 'competências' no sentido plural referem-se ao conjunto de conhecimentos e domínios articulados ao mundo produtivo e à organização do trabalho. As competências são potencialmente instáveis, exigem validação permanente, valorizam os atributos individuais, têm caráter experiencial e colocam as potencialidades no centro da divisão do trabalho. A adesão ao modelo pedagógico das competências envolve o reordenamento social das profissões para atender ao mercado flexível; significa formar o aluno para um novo profissionalismo no contexto político-econômico neoliberal (Ramos, 2001).

O SUS, na condição de maior empregador no setor saúde, tem imbricadas em sua rede de ações e serviços as contradições da formação profissional para o mundo do trabalho em crise. Tal constatação não significa renunciar aos princípios ideológicos ou deslegitimar o SUS; ao contrário, significa refletir sobre o caminho percorrido conjugando uma dupla articulação: apontar para a necessidade de mudanças estruturais na sociedade e investir na formação de sujeitos preparados para as mudanças. Em se tratando de uma crise paradigmática, requer desenvolver novas ideias sobre o processo educativo, ouvir novas vozes, fugir das obviedades, até porque o óbvio todo mundo vê, e fugir também dos pacotes institucionais totalizantes - estes não admitem singularidades. Implica problematizar a própria prática social, não como uma ação natural, muito menos neutra, mas como um processo de militância, com um novo olhar, mais atento e ambicioso, sobre os sujeitos e suas práticas.

Deste ponto em diante, este artigo propõe o 'roubo criativo' de conceitos que sinalizem um novo pensar na saúde. Na visão deleuziana, filosofia é a ciência dedicada à criação de conceitos, e os conceitos são criados em decorrência das contribuições de outros conceitos. Para Deleuze, trata-se de um roubo criativo na medida em que sempre permite apropriações e transformações. Isto posto, o esforço epistemológico pretende situar o trabalho e a educação em saúde no âmbito da relação ontológica humana e creditar nas ações diretas, por mínimas que sejam, a possibilidade de transformação da realidade (Gallo, 2008).

Adotando o roubo criativo como exercício epistemológico, utilizamos a matriz conceitual de 'professor reflexivo' inaugurada por Donald Shön e a revisão do conceito na dimensão mais coletiva adotada por Pimenta e Ghedin (2002). A crítica do conceito procura expandir os atributos do professor reflexivo para a reflexividade na prática educacional. Nesse enfoque potencializador, um novo diálogo se estabelece com o 'professor militante'. Para Gallo (2008), militante é o professor que não só apresenta a crítica da 
realidade, mas mergulha na miséria dos seus alunos para construir possibilidades coletivas de mudanças. Esse processo de libertação, de educação revolucionária, acontece nas relações que o professor trava no ambiente social com a 'educação menor e os rizomas'. Estes conceitos criados por Gilles Deleuze e Felix Guattari foram apropriados por Silvio Gallo (2008), e pelo exercício do pensamento deslocados para a educação.

\section{A educação permanente sob o olhar do profissional reflexivo}

O desenvolvimento da reflexividade na prática docente não é novo no Brasil. Na década de 1960, estava presente no movimento ver-julgar-agir da ação católica com o objetivo de desenvolver a consciência crítica dos militantes. Na década de 1970, a reflexividade foi proposta por Paulo Freire na ação-reflexão-ação; o método abria a possibilidade de análise crítica em torno da realidade codificada. Já os anos 1980 aproximaram a reflexão da dialética marxista referente à práxis - a dialética compreendida por meio da realidade em movimento, do devir, da história, do concreto pensado. Também houve nessa década a reflexão fenomenológica segundo a qual toda ação era interpretada como intencional, o homem como criador de significados, e a reflexão dependia do sentido dado a essa realidade (Pimenta e Ghedin, 2002).

Em razão da necessidade de incorporar o conceito de reflexão na formação do professor, a obra de Donald Schön, Educating the reflective practitioner, editada originalmente em 1987 (Schön, 2000), ganhou popularidade e tornou-se uma referência no âmbito educacional. A proposta de Schön visava romper com o modelo hegemônico de racionalidade técnica por meio da valorização da prática reflexiva e do professor pesquisador da prática. Segundo o autor, a reflexão referia-se à habilidade no ato de ensinar desenvolvida no cotidiano da sala de aula. Esse conhecimento estava intrínseco na prática, de forma tácita e sistemática. Assim, a interação teoria-prática proporcionava o processo de reflexão na ação e reflexão sobre a reflexão na ação. A produção do conhecimento era resultante das análises e interpretações da própria prática (Pimenta e Ghedin, 2002).

Novas leituras e apropriações vêm se agregando à proposta inaugural de Schön. A revisão do conceito procura retirá-lo do individualismo (autorreflexão), da adjetivação (qualidade de ser reflexivo), do modismo (apropriação distorcida) e da banalização (senso comum). O reducionismo da prática individual tende a ofuscar a dimensão conjuntural, política e crítica do conceito. A proposta, segundo os autores revisionistas, deve extrapolar a experiência pessoal para a dimensão coletiva (reflexão crítica), em que o movimento da realidade é captado para construção de um devir. Neste aspecto, há de se 
considerar a necessidade do suporte teórico na reflexão abrangendo o papel formativo, a capacidade de mediação com outras análises e os limites epistemológicos (Pimenta e Ghedin, 2002).

Além da prática docente, a reflexividade deve estar presente na formação de todo profissional. A reflexão na vertente crítica implica conhecer. O conhecimento propõe aplicabilidade sobre a realidade a fim de transformá-la. Essa concepção de aprendizagem que envolve a ação-reflexão-ação não pode se restringir às imposições curriculares das políticas educacionais. A reflexão, antes de ser uma qualidade individual, precisa ser compreendida como um caminho dialético e dialógico do conhecimento. A integração de saberes e práticas deve transcender o individualismo epistemológico para a experiência do conhecimento compartilhado em compromisso com o coletivo (reflexão crítica). É a práxis que retroalimenta os saberes e práticas norteadores do ato de cuidar. O envolvimento do profissional nesse processo é ação política que exige compromisso com o coletivo; é, sobretudo, mobilizar a teoria para incidir e intervir sobre a realidade, considerando teoria e prática como processos indissociáveis que têm limites políticos, institucionais, teóricos e metodológicos (Pimenta e Ghedin, 2002).

A formação reflexiva não se restringe a uma área disciplinar; ela é a superação da prática alienante. Em razão dessa natureza construtiva, não admite submissão aos entrincheiramentos disciplinares e pragmáticos. Como elemento constitutivo, ela atravessa os conteúdos, de modo não estático ou rígido, mas pela fluidez e pela interlocução com a realidade. Logo, podemos considerar que a reflexão é um processo coletivo que comporta saberes não disciplinares e admite apropriações nos diversos espaços em contextos históricos distintos de forma autônoma.

A partir dessa reconversão (termo utilizado por Pimenta e Ghedin, 2002), torna-se possível trazer a reflexão como ferramenta para a educação permanente na saúde. Na ótica reflexiva crítica, o trabalhador dotado de suporte teórico poderá enxergar as iniquidades, as novas formas de exploração e sofrimento, não apenas no âmbito da saúde como também na dimensão econômico-estrutural da sociedade. A aprendizagem na dinâmica do trabalho capacita o profissional para compreender a relação saúde-doença como um fenômeno integralmente biológico e sociocultural, e a partir dessa constatação postular um novo agir. Portanto, o exercício pedagógico nessa conjuntura, seja na sala de aula, seja no local de trabalho ou em espaços coletivos, deve estabelecer o diálogo entre os saberes disciplinares, os não disciplinares e as subjetividades e a realidade vivida. Este é o grande desafio da educação permanente no SUS.

Institucionalizar a educação permanente no setor saúde é a meta apresentada no corpo do texto da Política Nacional de Educação Permanente em Saúde (PNEPS), elaborado pelo Ministério da Saúde (Brasil, 2007). Mas de 
qual educação permanente falamos? Sobre quais pilares pedagógicos e ideológicos ela se assenta? Parece que mais uma vez há desmemória sobre a prática social que envolve o ato de educar, sua ação política interventora, jamais neutra. Como conceito, a educação permanente estabelece idas e vindas das mais diversas e conflitantes, do pensamento anárquico à reconstrução desenvolvimentista do pós-guerra. Hoje, no panorama da saúde, vigora um discurso institucionalizado com diretrizes e metas; a assimilação desse discurso pode corresponder à instrução profissional, jamais à educação. Esta se consolida no 'chão', seja da escola, seja da fábrica ou das unidades de saúde, nas relações microssociais. Sobre essa problemática, Silvio Gallo (2008) desenvolve em sua obra Deleuze e a educação importantes deslocamentos da filosofia de Deleuze e Guattari6 para as questões educacionais.

\section{A educação permanente sob o prisma da educação menor e dos rizomas}

De fato, a interface trabalho e educação comporta uma tensão conflituosa que este artigo tenta desvelar. O fomento à expansão do ensino superior, com todo o investimento na produção do conhecimento científico, voltado para a elevação da escolaridade do trabalhador em atenção ao modo produtivo. Essa estrutura fragmenta a produção de pesquisa do mundo do trabalho, prescreve a política educacional por parâmetros, diretrizes, avaliação de desempenho, monitoramento, metas e produção, num rentável mercado de profissionalização em massa.

Nesse sentido, a educação permanente é considerada pelo Ministério da Saúde um conceito pedagógico que visa efetuar relações orgânicas entre ensino, ações e serviços, e entre docência e atenção à saúde. Trata-se de aprendizagem significativa no trabalho, pois propõe problematizar a realidade vivenciada objetivando transformar as práticas de trabalho e a organização do processo de trabalho (Brasil, 2007). Paira sobre a PNEPS uma grande expectativa em relação à superação do modelo disciplinar. No entanto, a interdisciplinaridade, em lugar de romper com a organização da aprendizagem disciplinar, reafirma a disciplinarização dos saberes ao propor sua integração por meio de uma 'costura' artificial. Antes de se buscar a complexidade da aprendizagem, cabe investir na simplicidade do aprender e sua total resistência aos confinamentos metodológicos (Gallo, 2008).

Sem dúvida, as relações de trabalho abarcam na dinâmica cotidiana um grande potencial educativo interdisciplinar, com ricas abordagens a serem problematizadas nos espaços de aprendizagem, mas não podemos minimizar a pluralidade dos atores, a singularidade dos espaços, as resistências, os conflitos e lutas de poder. Tais especificidades nas microrrelações não se ajustam na totalidade ao projeto educativo cujo desenho pedagógico e gestão da 
estratégia sejam verticalizados. Sobre essa problemática, Alves e Garcia (2008, p. 10) indagam: “Como atender à recomendação de atuar disciplinarmente em uma parte do tempo de aula e, de repente, como num passe de mágica, deve assumir uma postura transdisciplinar nos chamados temas transversais?" O questionamento das autoras nos faz refletir: a manutenção de uma postura inter ou transdisciplinar no espaço de trabalho exige um esforço hercúleo na prática docente, uma vez que sua própria matriz formativa foi estruturada num modelo hegemonicamente disciplinar. Mais do que tutelar os professores com pacotes didáticos, metodologias e normatizações, convém primeiro flexibilizar a disciplinarização dos conteúdos e investir na 'educação permanente dos educadores', a fim de que eles adquiram habilidades e confiabilidade na proposta.

Em contrapartida, existe a possibilidade de subverter a educação permanente institucionalizada pela 'educação menor'. Menor porque acontece nas microrrelações, no movimento essencialmente cotidiano. A educação menor não é valorativa, nem significa o grau de importância linguístico; refere-se à subversão ao modelo formal instituído. Ela existe em todo espaço de conhecimento, se estabelece na margem do modelo 'maior', emerge do conflito; sua criação possui deformações denunciantes da dominação espacial, da opressão institucional e da insignificância humana (Gallo, 2008).

Deleuze e Guattari, ao analisarem os escritos de Kafka, apontaram três características: a desterritorialização, o caráter político e o valor coletivo. Para os autores, a literatura de Kafka não prevê beleza; é mais um testemunho avassalador da realidade, uma denúncia. Por ser menor, a literatura resiste, age nas brechas, nos desertos e nas misérias; expande-se na transversalidade e difunde-se em gotas tenuíssimas. Nessa busca por rupturas, nos modelos, diretrizes e preceitos institucionais, Gallo procura amalgamar os conceitos de literatura menor e rizomas desenvolvidos por Deleuze e Guattari às questões educacionais: "Sem a intencionalidade de criar modelos, propor caminhos, impor soluções, não se trata de buscar a integração dos saberes, mas fazer rizomas, viabilizar conexões sempre novas, criativas e criadoras" (Gallo, 2008, p. 76).

A educação menor não se submete ao paradigma arbóreo do conhecimento; o novo pensar requer a plasticidade rizomática. Rizoma7 significa um tipo de caule radiciforme de alguns vegetais, formado por uma miríade de pequenas raízes emaranhadas em meio a pequenos bulbos armazenatícios. Na lógica deleuzeana, os rizomas não permitem rigidez sistemática e organização disciplinar, não têm início, nem fim. São regidos por seis princípios básicos: conexão - nos rizomas há um emaranhado de conexões que estabelecem sempre novas conexões; heterogeneidade - as conexões permitem o encontro de diferentes naturezas; multiplicidade - o rizoma não se reduz à unidade, 'não é sujeito nem objeto, mas múltiplo'; ruptura a-significante - o rizoma 
não se afirma na previsibilidade, sustenta-se também pelas rotas de fuga; cartografia - o mapeamento dos rizomas revela algo a ser explorado, o devir; e decalcomania - os rizomas não são cópias, eles possibilitam transposições dinâmicas dos mapeamentos (Gallo, 2008, p. 76-78).

Para Gallo (2008, p. 67-68), a aprendizagem está além de qualquer controle, portanto é sempre possível desterritorializar os princípios da reflexão crítica, da educação menor e do crescimento de rizomas para as práticas educativas em saúde. A educação permanente na perspectiva 'menor' viabiliza a transversalidade dos saberes que circulam nos espaços de forma não disciplinar, já que os saberes fragmentados não dão conta de apreender a singularidade que abarca cada ser humano em suas relações sociais. Gallo (2008, p. 67-68) utiliza as seguintes expressões para a educação menor: "ela cria trincheiras"; "ela mina os espaços", "deve-se fazê-la como máquina de guerra e não aparelho de estado". Podemos perceber nas expressões do autor que o processo educacional se efetiva no campo de batalha composto por interes-ses distintos e conflitantes. Este é o papel do professor/profissional militante: desterritorializar os princípios e normas para criar estratégias de emancipação pelas brechas.

As diretrizes operacionais da PNEPS (Brasil, 2007) visam à aprendizagem-trabalho para os seguintes objetivos: transformar as práticas; reorganizar o processo de trabalho; promover a autonomia pedagógica; economizar com investimentos educacionais externos; estabelecer a ideia de rede de cuidado etc. Longe de se prescrever uma resolutividade, uma finalidade pragmática, a educação na saúde precisa provocar inquietações no trabalhador, desinstalá-lo da área de conforto, torná-lo sujeito pensante de suas práticas para construção do aprendizado coletivo; são agenciamentos para uma estrutura dinâmica do conhecimento. Mas que agenciamentos vigoram na transformação de um projeto político em processo educacional permanente? A decisão política de estabelecer educação ao longo da vida do trabalhador do SUS tem-se configurado hoje como um processo contínuo de vigilância, controle social e avaliação de desempenho. Mais uma vez, a educação imbricada nas relações de poder.

\section{Conclusão}

O SUS é uma escola. Mas de qual escola falamos? Dessa rígida e tutelada pelos interesses hegemônicos ou daquela emancipada, potencializadora, na contramão dos processos de dominação? Como afirma o próprio Deleuze em entrevista a Deschamps (1980): “O bom não está nunca assegurado. Não basta um espaço liso para vencer as estrias e os constrangimentos, nem um corpo sem órgãos para vencer as organizações". Postular um sistema educa- 
cional aberto pela via normativa não assegura a transformação de práticas e vivências.

Embora a formação privilegie uma racionalidade voltada para o mercado de trabalho, esse mesmo mercado de trabalho não é revelado em sua inteireza para o estudante. O ensino superior, após a década de 1980, atendeu à demanda do mercado como uma "máquina fornecedora de profissionais especializados e empregados subalternos" (Snyders, 2005, p. 97). Logo se conclui que a sociedade neoliberal exige e proporciona o aumento da escolaridade para uma realidade de incerteza, sem envolver aumento de reflexividade para o trabalhador. "(...) tanto a quantidade como a qualidade da mão de obra formada são determinadas pelos interesses a curto prazo dos monopólios" (Snyders, 2005, p. 97).

O ensino na saúde implica não só transformação da prática, mas principalmente investimento cognitivo para ampliar o sentido dessas práticas. Durante muito tempo, o olhar profissional se reduziu à doença, ao órgão acometido patologicamente, a aprendizagem estruturada nas intervenções técnicas, no arcabouço teórico, nos protocolos e consensos analíticos. Hoje já se fala em outras ações terapêuticas, a dança, a música, o riso, a fé, o esporte, o ambiente, o alimento, a família, os animais, os sonhos - signos que possibilitam novas respostas celulares, conexões alternativas, sinapses autorregenerativas, reação a sistemas invasivos etc. Olhar para essas potencialidades significa reaprender a pensar a saúde e o cuidado.

Ora, se as práticas assistenciais de saúde exigem do profissional uma reconversão de seu olhar, por que as práticas pedagógicas resistem ao status quo hegemônico? Poderíamos afirmar que, por existir a PNEPS, algo será significativamente aprendido? O ensino deve estar conectado à aprendizagem; a expressão ensino-aprendizagem traz em si a intermediação, como afirma Deleuze, entre o estado de não saber e o de saber: "A passagem viva de um ao outro estado" (Gallo, 2008, p. 66). Essa tarefa infinita extrapola os métodos e se efetiva pela margem.

Para além de uma proposta verticalizada, macrodimensional, a educação permanente precisa 'alcançar o chão', tornar-se menor, sub(versiva), outsider, para estabelecer rupturas capilares nas teias de poder. A resistência não se firma na negação do modelo educacional institucionalizado, mas na recriação de um novo sentido de compreensão, novos mapeamentos em direção à pulverização do saber reflexivo.

Embora a educação permanente suscite os saberes da prática, há de se estabelecer uma composição aberta, singular e rizomática. Um rizoma não começa nem chega a nenhum lugar; ele está sempre no meio, entre as coisas. Por maiores que sejam os desafios, sem menosprezar a crise societal (paradigmática), há sempre a possibilidade de infinitos caminhos que levam a vários lugares. Rotas de fuga em novas direções e outras não tão novas 
assim. O importante é ressignificar, apropriar-se de um novo olhar para o sujeito e para a coletividade rumo à desalienação na forma de cuidar e de conceber saúde em toda a sua inteireza estética.

\section{Colaboradores}

Renata de Lima Pacheco Nideck concebeu e redigiu este artigo, enquanto que Paulo Pires Queiroz colaborou em todas as etapas de elaboração do artigo.

Resumen El artículo aborda la educación permanente desde la óptica reflexiva y rizomática, abarcando la necesidad de desterritorializar los saberes que circulan en la salud. Se trata de una investigación bibliográfica cuya referencia teórica se estructura en el materialismo histórico marxista. El estudio describe un breve historial sobre la política educacional en base a dos eventos relevantes que ocurrieron en la década de 1980: la escasez de trabajadores para el trabajo complejo, denominado 'apagón educativo', y el surgimiento de la nueva enseñanza superior en Brasil. Tales eventos, al penetrar la formación profesional, reproducen en la educación en servicio la estructura del conocimiento más jerarquizada. Si la enseñanza en salud presenta limitaciones, también ofrece posibilidades y perspectivas para romper con la rigidez epistemológica y aproximarse a la educación menor y al crecimiento de rizomas en las prácticas en salud.

Palabras clave educación permanente; SUS; profesional reflexivo; educación menor; pedagogía rizomática. 


\section{Notas}

1 Fundação Municipal de Saúde de Niterói, Niterói, Rio de Janeiro, Brasil.

Mestranda em Enfermagem pela Universidade Federal Fluminense.

$<$ reini@ig.com.br>

Correspondência: Rua Laurentina Alves Pereira, 85, CEP 24320-070, Pendotiba, Niterói, Rio de Janeiro, Brasil.

2 Universidade Federal Fluminense, Niterói, Rio de Janeiro, Brasil. Doutor em Filosofia e Humanidades pela Columbia Pacific University.

<ppqueiroz@yahoo.com.br>

3 O termo 'classe-que-vive-do-trabalho' foi utilizado por Ricardo Antunes (2009) em referência à expressão marxista 'classe trabalhadora', no sentido de conferir validade contemporânea. Esse termo engloba o ser social que trabalha. São trabalhadores produtivos, que produzem diretamente mais-valia, e trabalhadores improdutivos, aqueles cujas formas de trabalho são usadas como serviços, seja para uso público, seja para o capitalista. Segundo Marx, o trabalho improdutivo é consumido como valor de uso e não como trabalho que cria valor de troca. O trabalho improdutivo abrange um amplo leque de assalariados, como aqueles inseridos no setor de serviços, em bancos, comércio, turismo, serviços públicos etc. (Antunes, 2009).

4 A sociedade do conhecimento surgiu nos países periféricos a partir da década de 1990. Caracteriza-se por mudança veloz, descontinuidade, incerteza. Sob a ditadura não mais política mas do mercado, as reformas educacionais responderam com a pedagogia das competências e as estruturas de formação flexíveis, como "a galinha dos ovos de ouro" para preparar o indivíduo não mais para o emprego, mas para a empregabilidade (Frigotto, Ciavatta e Ramos, 2009, p. 9).

5 O encontro de Alma-Ata aconteceu no Cazaquistão por ocasião da Conferência Internacional sobre Cuidados Primários de Saúde, com o tema "Saúde para todos no ano 2000". Participaram do evento mais de 130 países, que assinaram no término dos trabalhos uma declaração que ficou conhecida como Declaração de Alma-Ata. O documento celebrava o compromisso de todos os governantes ali presentes de estabelecer uma agenda no sentido de construir um novo paradigma para a saúde mundial.

6 Deleuze e Guattari são reconhecidos como filósofos da geração de 1968. Ambos não se dedicaram à filosofia da educação de forma veemente, como um profeta que do alto do deserto anuncia o porvir. Suas contribuições, conforme Gallo (2008) bem explicita, vêm de forma marginal, pela experiência de uma vida dedicada ao ensino e pela fecundidade do pensamento militante. Militância capaz de fazer o indivíduo mergulhar nas misérias do mundo, nas mais diversas misérias, para então estabelecer processos de libertação. Em defesa da filosofia criadora, e não reprodutora, vislumbram a oportunidade de intervir no mundo pela criação de conceitos; tanto Deleuze quanto Guattari veem nos conceitos imanentes da filosofia poderosos dispositivos de transformação da realidade.

7 Zourabichvili (2009), em sua análise sobre o vocabulário de Deleuze, no verbete 'rizoma' afirma que o conceito não configura um método. Criado por Deleuze e Guattari, esse conceito de rizoma significa um manifesto. O rizoma não tem início, nem fim. Não deve ser confundido com a comunicação; é um antimétodo que parece tudo autorizar. O seu rigor está justamente na autorização plena de permitir caminhos 
para o pensamento sob três pilares: “1. Pensar não é representar; 2 . Não há começo real para o aprendizado, ele se instala no meio; 3. Todo encontro é possível e não admite exclusão de nenhum caminho para o conhecimento" (Zourabichvili, 2009). Para Zourabichvili, o rizoma é tão benevolente quanto seletivo: ele tem a crueldade do real, e só cresce onde efeitos determinados têm lugar.

\section{Referências}

ALVES, Nilda; GARCIA, Regina L. (Orgs.). $O$ sentido da escola. 5. ed. Petrópolis: DP et Alii, 2008.

ANTUNES, Ricardo. Trabalho e precarização numa ordem neoliberal. In: FRIGOTTO, Gaudêncio. Cidadania negada: políticas de exclusão na educação e no trabalho. Rio de Janeiro: Cortez, 2001. p. 35-48. (Capítulo 2).

ANTUNES, Ricardo. A dialética do trabalho: escritos de Marx e Engels. São Paulo: Expressão Popular, 2004.

ANTUNES, Ricardo. Os sentidos do trabalho: ensaios sobre a afirmação e a negação do trabalho. 2. ed. São Paulo: Boitempo, 2009. (Mundo do Trabalho).

APPLE, Michael W. Para além da lógica do mercado: compreendendo e opondo-se ao neoliberalismo. Rio de Janeiro: DP\&A, 2005.

ASSUNÇÃO, Ada A.; BRITO, Jussara (Orgs.). Trabalhar na saúde: experiências cotidianas e desafios para a gestão do trabalho e do emprego. Rio de Janeiro: Editora Fiocruz, 2011.

BOSI, Antônio P. A precarização do trabalho docente nas instituições de ensino superior do Brasil nesses últimos 25 anos. Educação \& Sociedade, Campinas, v. 28, n. 101, p. 1.5031.523, set./dez. 2007. Disponível em: <www. scielo.br/pdf/es/v28n101/a1228101>. Acesso em: mar. 2012.
BRASIL. Lei n. 8.080, de 19 de setembro de 1990. Dispõe sobre as condições para a promoção, proteção e recuperação da saúde, a organização e o funcionamento dos serviços correspondentes e dá outras providências. Disponível em: <www.planalto.gov.br/ccivil_ 03/leis/18080.htm>. Acesso em: mar. 2012.

BRASIL. Ministério da Saúde. Portaria do Gabinete do Ministro n. 1.996, de 20 de agosto de 2007. Dispõe sobre as diretrizes para implementação da Política Nacional de Educação Permanente em Saúde - PNEPS e dá outras providências. Brasília, 2007. Disponível em: <http://dtr2001.saude.gov.br/sas/ PORTARIAS/Port2007/GM/GM-1996.htm>. Acesso em: abr. 2012.

BRASIL. Ministério da Saúde. Relatório Saúde Brasil 2009: uma análise da situação de saúde e da agenda nacional e internacional de prioridades em saúde. Brasília: Ministério da Saúde, 2009. Disponível em: $<$ www.pnud.org.br/HDR/arquivos/rdh_ brasil_2009_2010.pdf>. Acesso em: abr. 2012.

DESCHAMPS, Christiam. Entrevista de Gilles Deleuze a Christiam Deschamps sobre o livro Mil platôs. 3 de outubro de 1980. Disponível em: <www.scribd.com/doc/55494307/MilPlatos-Nao-Formam-Montanha-EntrevistaGd\#page=1http: > . Acesso em: jan. 2012.

FARAGO, Cátia C.; SAMPAIO, Carlos M. o futuro do emprego é a qualificação? In: 
SEMINÁRIO NACIONAL DE SOCIOLOGIA \& POLÍTICA UFPR, 1. 2009. "Sociedade e política em tempos de incerteza". Disponível em: <www.humanas.ufpr.br/site/evento/ SociologiaPolitica/GTs-2009>. Acesso em: out. 2010.

FRIGOTTO, Gaudêncio; CIAVATTA, Maria; RAMOS, Marise. In: Unesco: International Handbook of Education for Changing World of Work. Bonn: Univoc, 2009. p. 1.307-1.319. (Coletânea organizada pelo Centro Internacional de Educação Técnica e Profissional, com o patrocínio da Unesco. Berlim, 2005).

GALLO, Silvio. Deleuze e a educação. 2. ed. Belo Horizonte: Autêntica, 2008.

INSTITUTO BRASILEIRO DE GEOGRAFIA E ESTATÍSTICA (IBGE). Censo Demográfico. IBGE, 2000. Disponível em: <www.ibge. gov.br/censo>. Acesso em: 05 out. 2012

MACHADO, Maria H.; OLIVEIRA, Eliane dos S.; MOYSÉS, Neuza M. Nogueira. Tendências do Mercado de Trabalho no Brasil. Disponível em: <www.ensp.fiocruz.br/ observarh/arquivos/TendenciasTrabalho. pdf>. Acesso em: 22 fev. 2013.

MARTINS, Carlos B. A reforma universitária de 1968 e a abertura para o ensino superior privado no Brasil. Educação \& Sociedade, Campinas, v. 30, n. 106, Apr. 2009. Disponível em: <www.scielo.br/pdf/es/v30n106/ v30n106a02.pdf $>$. Acesso em: 11 jun. 2014.

NEVES, Lúcia M. W.; PRONKO, Marcela A. $O$ mercado do conhecimento e o conhecimento para o mercado: a formação para o trabalho complexo no Brasil contemporâneo. Rio de Janeiro: EPSJV, 2008.
NUNES, Edson de O. Educação superior no Brasil: estudos, debates, controvérsias. Rio de Janeiro: Garamond, 2012.

PIMENTA, Selma G.; GHEDIN, Evandro (Orgs.). O professor reflexivo no Brasil: gênese e crítica de um conceito. São Paulo: Cortez, 2002.

RAMOS, Marise. Pedagogia das competências. In: PEREIRA, Isabel Brasil; LIMA, Julio César França. Dicionário de educação profissional em saúde. 2. ed. rev. ampl. São Paulo: Cortez, 2009. p. 299-305.

SALDANHA, Alessandra. SUS - Sistema Único de Saúde (esquematizado): lei n. 8.080/90, de 19 de setembro de 1990, incluída a lei n. 8.142/90 e comentários sobre as NOBs 91/93/96, Noas - SUS 01/2001 e 01/2002 e Pacto pela Saúde /2006. Rio de Janeiro: Editora Ferreira, 2011.

SANTOS, Boaventura de S. Pela mão de Alice: o social e o político na pós-modernidade. 12. ed. São Paulo: Cortez, 2008.

SCHÖN, Donald A. Educando o profissional reflexivo: um novo design para o ensino e aprendizagem. Tradução de Roberto Cataldo Costa. Porto Alegre: Artmed, 2000.

SNYDERS, Georges. Escola, classes e luta de classes. Tradução de Leila Prado. São Paulo: Centauro, 2005.

ZOURABICHVILI, François. O vocabulário de Deleuze. Rio de Janeiro: Relume Dumará, Sinergia, Ediouro, 2009 (Série Conexões 4).

Recebido em 06/04/2013

Aprovado em 06/10/2013 
